\title{
Non-Immunosuppressant Medication Use in Heart Transplant Patients: A Guide for Pharmacists
}

\author{
Gregory Egan1, Glen J. Pearson 2,3 \\ ${ }^{1}$ University of British Columbia, Vancouver, British Columbia, Canada \\ ${ }^{2}$ University of Alberta, Division of Cardiology, Edmonton, Alberta, Canada \\ ${ }^{3}$ Mazankowski Alberta Heart Institute, Edmonton, Alberta, Canada \\ Email: Glen.Pearson@ualberta.ca
}

Received 29 July 2014; revised 2 September 2014; accepted 19 September 2014

Copyright (C) 2014 by authors and Scientific Research Publishing Inc.

This work is licensed under the Creative Commons Attribution International License (CC BY).

http://creativecommons.org/licenses/by/4.0/

(c) (i) Open Access

\begin{abstract}
For heart transplant patients, there are a number of non-immunosuppressant medications that are routinely prescribed to mitigate the side-effects of immunosuppression, treat the related complications, and improve long-term survival. This review focuses on the medications used to prevent and manage cardiac allograft vasculopathy (CAV), hypertension, dyslipidemia and osteoporosis. The rationale and evidence supporting their use are summarized and the immunosuppressant drugs are only discussed briefly, as they relate to each of these medical issues. Pharmacy practitioners are likely to encounter patients post-cardiac transplant in a variety of clinical settings; therefore, a concise appreciation of the principles for the long-term medical management of these patients is important when providing collaborative care.
\end{abstract}

\section{Keywords}

Cardiac Transplant, Cardiac Allograft Vasculopathy, Calicneurin Inhibitors, Hypertension, Dyslipiemia, Osteoporisis

\section{Introduction}

The overall survival for heart transplant recipients after cardiac-allograft transplantation is continuously improving, with current survival rates of $95 \%$ at 3 months, $90 \%$ at 1 year, $75 \%$ at 5 years and $50 \%$ at 10 years [1]-[3]. Due to improvements in organ procurement/preservation, newer immunosuppressant therapies and optimization of post-transplant management and follow-up, patient survival rates steadily improve [1]-[4]. As a result, pharmacy practitioners are likely to encounter patients post-transplant in a variety of clinical settings. 
Consequently, a concise appreciation of the principles for the long-term medical management for cardiac transplant is important when providing collaborative care.

Heart transplantation is a medical intervention that is indicated for end-stage heart disease due to irreversible causes and anticipated life expectancy of less than 1 year [5]-[7]. Typically, these patients have advanced symptoms of heart failure, New York Heart Association (NYHA) Class IIIb or IV (Table 1), which is refractory to optimal medical management [5]-[7]. Patients with life-threatening, drug resistant ventricular tachycardia or ventricular fibrillation, may also be considered for heart transplantation [6] [7].

This review focuses on the medications used to prevent the potential long-term complications in post-cardiac transplant patients including, cardiac allograft vasculopathy (CAV), hypertension, dyslipidemia and osteoporosis. The use of immunosuppressant drugs is critical in the long-term survival of these patients and their careful monitoring and adjustment are necessary to minimize complications. However, immunosuppressant agents are individually selected and managed exclusively by clinicians with expertise in heart transplantation- this is the role of the patient's heart transplant team. The immunosuppressant drugs will only be discussed briefly in each section, as it relates to issues emphasized in this review.

\section{Cardiac Allograft Vasculopathy}

$\mathrm{CAV}$ is a type of chronic rejection which is an important prognostic factor for long-term survival for heart transplant recipients [8]. It is the most common cause of mortality in first year post-transplant, with an incidence of up to $50 \%$, and accounts for $\sim 20 \%$ of transplant recipient mortality [8]-[10]. CAV is the most common reason for re-transplantation [3]. CAV has a diffuse pattern of concentric intimal proliferation and luminal stenosis with a progression to total occlusion of the smaller, distal portions of the coronary arteries [8]-[10].

The etiology of CAV is multifactorial, with both immune and non-immune pathogenic factors implicated [8]. It occurs more frequently in patients with poor immunologic match; therefore, the alloimmune response appears to play a central role in the pathogenesis of CAV [8]-[10]. The non-immunologic factors which may contribute include: cytomegalovirus (CMV) infection, associated toxicities of the immunosuppressant drugs, and the traditional, modifiable risk factors for coronary artery disease (CAD) (hypertension, dyslipidemia and diabetes) [9] [11].

The International Society for Heart and Lung Transplant (ISHLT) and Canadian Cardiovascular Society (CCS) guidelines for cardiac transplant recommend surveillance for CAV with coronary angiography and intravascular ultrasound (IVUS) at 4 - 6 weeks, and 1-year post-transplant [6] [7]. In a prospective cohort of patients who underwent angiography and PCI for CAV, due to the diffuse nature of disease, PCI was successful in only $50 \%$ of patients and mortality rates were the comparable to the expected mean survival [7] [12]. Additionally, use of non-invasive monitoring (dobutamine stress echocardiography or myocardial perfusion scan) is unreliable for diagnosis and monitoring of CAV as the diffuse pattern of disease results in a high rate of false negatives [6] [7] [11]. Ultimately, the key to managing CAV is to prevent progression with medical therapy.

Induction immunosuppression, given in the first several days post-transplant, decreases the risk of CAV compared to not using induction [6] [7] [13]. Specifically, the use of antithymocyte globulin (ATG) for this purpose, has been shown to reduce the absolute risk of CAV on angiography at 1-year by 20\% compared to older agents (muromonab-CD3 [OrthocloneOKT3 ${ }^{\circledR}$ ]) [13]. At 10-years post-transplant ATG reduces absolute risk of CAV by $25 \%$ compared to IL-2 monoclonal antibodies [14]. However, survival was not significantly different between agents in any of these studies.

Calcineurin inhibitor (CNI)-based (cyclosporine and tacrolimus) immunosuppressive regimens are associated with toxicity of pancreatic beta-cells, inhibition of cholesterol metabolism and sodium retention [15] [16].

\begin{tabular}{cc} 
Table 1. New York Heart Association (NYHA) functional classification [1] [5] [6]. \\
\hline Class & \multicolumn{1}{c}{ Patient Symptoms } \\
\hline I & Cardiac disease but no symptoms or limitations in ordinary physical activity. \\
II & Mild symptoms of dyspnea or angina and slight limitation to ordinary physical activity. \\
III & Symptoms limited even less than ordinary physical activity and symptom-free only at rest. \\
IV & Experiences symptoms even while at rest, mostly bedbound. \\
\hline
\end{tabular}


Therefore, the risk of developing diabetes, dyslipidemia and hypertension is increased with the life-long use of immunosuppressant drugs to prevent rejection of the donor heart. In general, the use of sirolimus compared to tacrolimus or cyclosporine, and newer agents such as mycophenolate mofetil and everolimus are associated with a relatively lower risk of developing CAV [9] [15]-[19]. Corticosteroids (CS) are routinely following heart transplantation and then usually tapered over 6 - 12 months. Pulse-doses of steroids may also be used intermittently to treat minor acute rejection episodes. CS increase the release of cortisol which stimulates appetite, decreases insulin release, up-regulate the activity of 3-hydroxyl-3-methylglutaryl-coenzyme A (HMG-CoA) which increases LDL and VLDL synthesis and release [20]. CS increase the risk of developing diabetes, hypertension and dyslipidemia [20]. While the effect of CS on CAV has not directly been studied, it logically follows that the use of CS increases the risk of CAV in this population.

The use of non-dihydropyridine calcium-channel blockers (CCB) or angiotensin converting enzyme inhibitors (ACEi) decreases the degree of vascular intimal hyperplasia, compared to no therapy, as measured by IVUS at 1-year [21]. The angiotensin receptor blocker (ARB), eprosartan, was compared to diltiazem as part of a routine post-transplant regimen and IVUS at 2 years confirmed a non-statistically significant different in plaque volume [22]. Clinical studies, along with numerous animal models, suggest that the use of ACEi, ARBs and/or CCBs may reduce the progression of CAV independent of blood pressure lowering effects by preventing intimal hyperplasia and fibroblast activation [23].

HMG-CoA reductase inhibitors, or statins, are the only class of medications that have demonstrated consistent reduction in CAV and prolong survival rates in heart transplant patients [6] [7]. There are numerous proposed mechanisms of action by which statins reduce the risk of CAV including: reduction of atherogenic lipid particles, reduction of reactive oxidative species which decreases vascular smooth muscle proliferation and increases the availability of nitric oxide which has an anti-inflammatory effect which reduces vascular intimal hyperplasia [24]. The seminal randomized control trial that compared routine post-transplant pravastatin therapy to no statin demonstrated a significant reduction in the incidence of rejection, CAV and mortality at 1-year, and the benefit persisted for 10 -years, with a $20 \%$ absolute risk reduction in mortality [25]. Subsequently, simvastatin and atorvastatin have been compared to pravastatin over 1-year and up to 5-years. The rates of rejection, mortality and CAV on angiogram were not significantly different between these agents [24] [26] [27]. The significant reduction in 1-year mortality is consistent across several trials and provides evidence that statins should be routinely used post-transplant regardless of the recipients' baseline lipid profile. The rate of rhabdomyolysis in cardiactransplant patients was reported to be less than $0.5 \%$ per patient-year in one large cohort study. In two recent large cohort studies using registry data statins are associated with achievement of the LDL-C goal of <2.6 $\mathrm{mmol} / \mathrm{L}$ in about $60 \%$ of patients and $12.2 \%$ of all transplant patients suffered adverse events and $3.9 \%$ of the patients permanently discontinued statin treatment [24] [25]. In practice, these patients are considered at highrisk for cardiovascular disease (CVD) and treated, where possible, to achieve the primary guideline target of an LDL-C of $<2.0 \mathrm{mmol} / \mathrm{L}$ [28].

In general, the best management of CAV is prevention with statin therapy immediately post-transplant and continued lifelong. Other traditional risk factors such as hypertension, diabetes and dyslipidemia should be treated. There are studies measuring surrogate markers for CAV that have shown decreased progression with ACEi, ARB and non-dihydropyridine CCB. Routine treatment with ACEi or CCB is common, but may not be continued unless there is another indication for their use.

\section{Hypertension}

The development of arterial hypertension after cardiac transplant is common, with the incidence of de novo hypertension around $17 \%$ annually and the prevalence in cohorts ranging up to $80 \%$ [29] [30]. The risk factors for the development of de novo hypertension long-term post-transplant stem from cardiac denervation (interruption of the sympathetic nerve connection to the heart as a result of surgical transplantation) which results in a decrease in parasympathetic tone and loss of the normal circadian variation in blood pressure [30] [31]. Immunosuppressant therapy with CS and CNI, cyclosporine in particular, increases the risk of sodium and water dysregulation and increased peripheral vascular resistance [31]-[33]. Independent predictors for the development of hypertension post-transplant include the following characteristics: male gender of the recipient or donor, idiopathic dilated cardiomyopathy as the etiology of heart failure, history of cigarette smoking, and hypercholesterolemia [33]. 
The ISHLT Guidelines recommend that recipients should have blood pressure controlled to $<140 / 90 \mathrm{mmHg}$ to prevent allograft damage [6]. The initial intervention for hypertension is lifestyle modifications such as weight loss, regular aerobic exercise, decrease sodium intake, and the dose minimization of immunosuppressive agents, particularly CS [6]. Clinical trials of pharmacotherapy for treating hypertension post-transplant are modest in size and generally underpowered to detect differences in clinical outcomes. In the largest RCT to date, which included 116 patients on cyclosporine followed over the first year post-transplant both diltiazem and lisinopril effectively reduced blood pressure by $25 / 10 \mathrm{mmHg}$; however, $<50 \%$ of patients overall achieved the target blood pressure of $\leq 130 / 80 \mathrm{mmHg}$ [34]. In a small study of 38 patients, treated with amlodipine or placebo over 1-year, the mean blood pressure reduction was $17 / 10 \mathrm{mmHg}$ and the development of proteinuria was significantly reduced with amlodipine [35]. Patients were treated regardless of hypertension at hospital discharge; however, patients with a blood pressure of $<110 / 60 \mathrm{mmHg}$ or a serum creatinine $>140 \mu \mathrm{mol} / \mathrm{L}$ at hospital discharge were excluded from the study.

No RCTs in cardiac transplant recipients have been large enough to compare clinical outcomes, particularly in relation to CVD of the cardiac allograft. An ACEi or diltiazem are the preferred antihypertensive agents and are commonly used, regardless of blood pressure, post-transplant [36] [37]. Diltiazem inhibits the metabolism of cyclosporine and tacrolimus by up to $50 \%$ and thus reduces the required dose of immunosuppressant to achieve target serum concentrations [36]. There is evidence that the use of antihypertensive regardless of baseline blood pressure reduces end-organ damage, such as nephropathy; however, further study is required before this strategy should be ubiquitously adopted.

\section{Dyslipidemia}

Cardiac transplant patients are at increased risk of dyslipidemia, with $80 \%$ prevalence reported. The risk factors for the development of dysplipdemia at 1-year post-transplant were cumulative prednisone dosage, body-mass index $>25 \mathrm{~kg} / \mathrm{m}^{2}$ and a pre-transplant diagnosis of CAD in one cohort study [38]. Besides traditional CAD risk factors, immunosuppressant medication use contributes to hyperlipidemia [39]. Cyclosporine increases LDL-C production by about $1 / 3$ from baseline; tacrolimus also increases serum LDL-C, but not to the same magnitude [30] [33]. Sirolimus and mycophenolate mofetil also increase serum cholesterol levels, but to a lesser magnitude than CS and cyclosporine. In general, the use of immunosuppressants should be minimized to mitigate the consequences of long-term dyslipidemia and cardiovascular (CV) risk.

The use of statins is ubiquitous in cardiac transplant patients, as previously reviewed, and the doses can be titrated to treat dyslipidemia and achieve high-risk targets. In a RCT of 97 patients, pravastatin started 1-2 weeks post-transplant at 1 year total reduced total cholesterol from $6.3 \mathrm{mmol} / \mathrm{L}$ to $5 \mathrm{mmol} / \mathrm{L}$, decreased progression of coronary intimal thickness and had an absolute risk reduction for mortality of 5\% [25] [40]. Head-to-head comparisons of statins (pravastatin, simvastatin and atorvastatin) in cardiac transplant demonstrate a differential effect on lowering LDL and total cholesterol (TC). Overall, atorvastatin was the most potent agent in terms of lipid lowering reducing LDL by $45 \%$ and TC by $33 \%$ when given at doses of $10-20 \mathrm{mg}$ per day [41]. This increase in lipid lowering did not translate into improved efficacy as clinical outcomes such as mortality and rejection were not statistically significant between atorvastatin and pravastatin as well as simvastatin and pravastatin [28] [41].

Studies demonstrate that co-administration of cyclosporine with statins can increase systemic exposure leading to increased adverse events, such as myalgias [42]-[45]. The nature of this interaction is complex and the result of the combination of cyclosporine inhibition of P-glycoprotein, CYP3A4 metabolism and organic-aniontransporter activity, as elevated levels of non-CYP3A4 metabolized statins, such as fluvastatin, pravastatin and rosuvastatin are reported [44]. In animal models, concurrent cyclosporine and rosuvastatin resulted in a 9-fold increase in rosuvastatin serum concentrations [46]. With concurrent atorvastatin therapy, cyclosporine did not significantly affect serum concentrations of atorvastatin or its metabolites [47]. Also, with concurrent tacrolimus and atorvastatin there was not an increased serum concentration of atorvastatin or its metabolites [46]. Despite these potential drug interactions, the occurrence of rhabdomyolysis is rare and documented with only case reports [42] [43]. However, to mitigate these potential drug-interactions between statins and immunosuppressant medications the recommended doses of statins areoften lower (Table 2).

If statins are not tolerated or dyslipidemia persists, treatment with ezetimibe may be considered. A cohort of 36 patients who did not tolerate statin therapy or cholersterol remained elevated ezetimibe $10 \mathrm{mg}$ was used [48]. 
Table 2. Maximum recommended doses of statins with calcineurin inhibitors [42]-[47].

\begin{tabular}{cc}
\hline Statin Agent & Maximum Dose \\
\hline Atorvastatin & $40 \mathrm{mg}$ \\
Simvastatin & $20 \mathrm{mg}$ \\
Rosuvastatin & Contraindicated \\
Pravastatin & $20 \mathrm{mg}$ \\
Fluvastatin & Caution \\
\hline
\end{tabular}

At 12 months of treatment TC was decreased from $6 \mathrm{mmol} / \mathrm{L}$ to $5 \mathrm{mmol} / \mathrm{L}$ and $\mathrm{LDL}$ decreased from $2.7 \mathrm{mmol} / \mathrm{L}$ to $2 \mathrm{mmol} / \mathrm{L}$ [48]. There were 2 patients that had to discontinue therapy due to hand edema and rhabdomyolysis. There were no rejections or deaths during the follow-up, however given the limitation of the study design conclusions cannot be made regarding clinical outcomes with ezetimibe.

Statins are routinely used in cardiac transplant recipients regardless of baseline cholesterol in order to decrease CV risk, mitigate the development of CAV and to increase survival. There are no clinical trials that compare different lipid targets and currently the ISHLT guidelines recommend that in cardiac transplant patients $\mathrm{LDL}<2.0 \mathrm{mmol} / \mathrm{L}$ and TC/HDL ratio $<4$.

\section{Osteoporosis}

The major contributing factor to rapid deficits in bone mass density (BMD) is the metabolic consequences of immunosuppressant medications, particularly CNI and CS [49] [50]. Use of CS suppress osteoblast function, enhances osteoclast activity, impairs collagen synthesis, decreases GI absorption of calcium and also inhibits pituitary secretion of growth hormone and insulin like growth factor [50]. Cyclosporine accelerates bone turnover and decreases circulating testosterone levels, thereby decreasing osteoblast function [49]. Tacrolimus causes greater relative bone-loss than cyclosporine [50]. The loss of BMD occurs particularly in the first year posttransplant as immunosuppressant therapy consists of regular CS and higher relative serum concentrations of CNI. One cohort study compared BMD from cardiac transplant patients at 60 days post-transplant to their expected BMD based on age and gender. BMD was significantly decreased by $15 \%$ over the short follow-up time [51]. During this time, heart transplant recipients are usually receiving high doses of CS-an example of one CS dosing regimen: prednisone $1 \mathrm{mg} / \mathrm{kg}$ initially, tapered to achieve dose of $\sim 0.3 \mathrm{mg} / \mathrm{kg}$ by 1-month, then $\sim 0.2 \mathrm{mg} / \mathrm{kg}$ by 2-months, then $0.1 \mathrm{mg} / \mathrm{kg}$ by 3-months, and final taper to wean off between $4-6$ months, where appropriate.

All cardiac transplant patients should receive adequate intake of calcium and vitamin D either through dietary sources and supplementation [51]. Bisphosphonates are used routinely during the first year post-transplant and the subsequent decision to continue long-term is based on individual fracture risk. The ISHLT guidelines recommend that a dual energy x-ray absorptiometry (DEXA) be obtained at baseline and repeated at 1-year posttransplant [6]. In a review on CS induced osteoporosis, the use of bisphosphonate resulted in less of a decrease in BMD and reduced fracture risk (OR 0.76, p < 0.005) [52]. There was no particular advantage to one bisphosphonate over another; therefore, heart transplant patients are treated with the least expensive agent covered by their particular drug plan.

The use of calcitonin has been studied in cardiac transplant patients in 2 small RCTs. A trial of 23 patients were randomized to calcitonin or no therapy, all patients received calcium and vitamin D supplementation. Follow-up occurred over 7 years with annual BMD scan and there was a statistically significant difference with higher BMD in the calcitonin group seen as early as 1-year [53]. In another trial of 18 patients randomized to calcitonin or calcitonin plus exercise immediately post-transplant there was a marginal increase in BMD at 8-months, although this was within the error limits for the DEXA scan used [54].

The clinical trials performed are underpowered to detect a difference in fracture rates. The evidence for the calcium and vitamin D intake is extrapolated from the general population and is continued life-long if tolerated. The use of bisphosphonates is based on the data from CS induced osteoporosis. All patients should receive bisphosphonates regardless of BMD for at least 1 year, at that point the decision to continue bisphosphonate is based on ongoing CS therapy and calculated fracture risk. 


\section{Conclusion}

For heart transplant patients, there are a number of non-immunosuppressant medications that are routinely used. These medications are used to mitigate the side-effects of immunosuppression, treat the related complications, and improve long-term survival. Each encounter with a cardiac-transplant recipient is an opportunity to confirm the non-transplant medications that they have been prescribed, provide education regarding these medications and monitor for drug-related problems (DRPs) such as drug-interactions, adverse events and compliance. It is important to always consider, that transplant patient outcomes are determined by carefully maintaining an intricate balance between organ rejection and drug toxicity. If a specific DRP is identified, consultation with the local transplant team should be pursued, as they will have the most up-to-date patient information and the greatest experience to help direct the individual patient's care plan and follow-up.

\section{References}

[1] Fischer, S. and Glas, K.E. (2013) A Review of Cardiac Transplantation. Anesthesiology Clinics, 31, 383-403. http://dx.doi.org/10.1016/j.anclin.2013.01.003

[2] Deng, M.C. (2002) Cardiac Transplantation. Heart, 87, 177-184. http://dx.doi.org/10.1136/heart.87.2.177

[3] Stehlik, J., Edwards, L.B., Kucheryavaya, A.Y., Aurora, P., Christie, J.D., Kirk, R., Dobbels, F., Rahmel, A.O. and Hertz, M.I. (2010) The Registry of the International Society for Heart and Lung Transplantation: Twenty-Seventh Official Adult Heart Transplant Report-2010. The Journal of Heart and Lung Transplantation, 29, 1089-1103. http://dx.doi.org/10.1016/j.healun.2010.08.007

[4] Lindenfeld, J., Page, R.L., Zolty, R., Shaker, S.F., Levi, M., Lowes, B., Wolfel, E. and Miller, G.G. (2005) Drug Therapy in the Heart Transplant Recipient: Part III Common Medical Problems. Circulation, 111, 113-117. http://dx.doi.org/10.1161/01.CIR.0000151609.60618.3C

[5] Thibodeau, J.T., Mishkin, J.D., Patel, I.C., Mammen, P., Warkham, D.W. and Drazner, M.H. (2012) IIIB or Not IIIb: A Previously Unanswered Question. Journal of Cardiac Failure, 18, 367-372. http://dx.doi.org/10.1016/j.cardfail.2012.01.016

[6] Constanzo, M.R. and Burch, M. (2010) The International Society of Heart and Lung Transplantation Guidelines for the Care of Heart Transplant Recipients. The Journal of Heart and Lung Transplantation, 29, 914-956. http://dx.doi.org/10.1016/j.healun.2010.05.034

[7] Haddad, H., Isaac, D., Lagare, J.F., Pfiugfelder, P., Hendry, P. and Chan, M. (2009) Canadian Cardiovascular Society Consensus Conference Update on Cardiac Transplantation 2008: Executive Summary. Canadian Journal of Cardiology, 25, 197-205. http://dx.doi.org/10.1016/S0828-282X(09)70061-3

[8] Crespo-Leiro, M.G., Marzoa-Rivas, R., Barge-Caballero, E. and Pariagua-Martin, M.J. (2012) Prevention and Treatment of Coronary Artery Vasculopathy. Current Opinion in Organ Transplantation, 17, 546-550. http://dx.doi.org/10.1097/MOT.0b013e3283577fd9

[9] Sanchez Lazaro, I.J., Bonet, L., Lopez, J.M., Lacueeta, S. and Martinez-Dolz, L.L. (2008) Influence of Traditional Cardiovascular Risk Factors in the Recipient on the Development of Cardiac Allograft Vasulopathy after Heart Transplantation. Transplantation Proceedings, 40, 3056-3057. http://dx.doi.org/10.1016/j.transproceed.2008.08.115

[10] Tona, F., Perazzolo, M., Fedrigo, M., Famoso, G., Bellu, R., Thiene, G., Gerosa, G., Angelini, A. and Iliceto, S. (2012) Recent Development on Coronary Microvasculopathy after Heart Transplantation: A New Target in the Therapy of Cardiac Allograft Vasculopathy. Current Vascular Pharmacology, 110, 206-215. http://dx.doi.org/10.2174/157016112799304987

[11] Valantine, H.A., Gao, S.Z., Menon, S.G., Renlund, D.G., Hunt, S.A., Oyer, P., Stinson, E.B., Brown, B.W., Merigan, T.C. and Schroeder, J.S. (1999) Impact of Prophylactic Immediate Posttransplant Ganciclovir on Development of Transplant Atherosclerosis: A Post Hoc Analysis of a Randomized, Placebo-Controlled Study. Circulation, 100, 61-66. http://dx.doi.org/10.1161/01.CIR.100.1.61

[12] Benza, R.L., Zoghbi, G.J., Tallaj, J., Brown, R., Kirklin, J.K., Hubbard, M., Rayburn, B., Foley, B., McGiffin, D.C., Pinderski, L.J., Misra, V. and Bourge, R.C. (2004) Palliation of Allograft Vasculopathy with Transluminal Angioplasty. Journal of the American College of Cardiology, 43, 1973-1981. http://dx.doi.org/10.1016/j.jacc.2004.02.045

[13] Zhang, R., Haverich, A., Struber, M., Simon, A. and Bara, C. (2008) Delayed Onset of Cardiac Allograft Vasulopathy by Induction Therapy Using Anti-Thymocyte Globulin. The Journal of Heart and Lung Transplantation, 27, 603-609. http://dx.doi.org/10.1016/j.healun.2008.02.016

[14] Bonaros, N., Dunkler, D., Kocher, A., Imhof, M., Grimm, M., Zuckermann, A., Wolner, E. and Laufer, G. (2006) Ten-Year Follow-Up of a Prospective, Randomized Trial of BT563/BB10 versus Anti-Thymocyte Globulin as Induction Therapy after Heart Transplantation. The Journal of Heart and Lung Transplantation, 25, 1154-1163. 
http://dx.doi.org/10.1016/j.healun.2006.03.024

[15] Dandel, M. and Hetzer, R. (2010) Impact of Immunosuppressive Drugs on the Development of Cardiac Allograft Vasculopathy. Current Vascular Pharmacology, 8, 706-719. http://dx.doi.org/10.2174/157016110792006923

[16] Guethoff, S., Meiser, B.M., Eifert, S., Grinninger, C., Ueberfuhr, P., Reichart, B., Hagl, C. and Kaczmarek, I. (2013) Ten-Year Results of a Randomized Trial Comparing Tacrolimus versus Cyclosporine A in Combination with Mycophenolate Mofetil after Heart Transplantation. Transplantation, 95, 629-634. http://dx.doi.org/10.1097/TP.0b013e318277e378

[17] Topilsky, Y., Hasin, T., Raichlin, E., Boilson, B.A., Schirger, J.A., Pereira, N.L., Edwards, B.S. and Clavell, A.L. (2012) Sirolimus as Primary Immunosuppression Attenuates Allograft Vasculopathy with Improved Late Survival and Decreased Cardiac Events after Cardiac Transplantation. Circulation, 125, 708-720. http://dx.doi.org/10.1161/CIRCULATIONAHA.111.040360

[18] Kaczmarek, I., Ertl, B., Schmauss, D., Sadoni, S., Knez, A., Daebritz, S., Meiser, B. and Reichart, B. (2006) Preventing Cardiac Allograft Vasculopathy: Long-Term Beneficial Effects of Mycophenolate Mofetil. The Journal of Heart and Lung Transplantation, 25, 550-556. http://dx.doi.org/10.1016/j.healun.2006.01.003

[19] Arora, S., Ueland, T., Wennerblum, B. Sigurdadottir, V., Eiskjaer, H., Botker, H.E., Ekmehag, B., Jansson, K., Mortensen, S.A. and Saunamaki, K. (2011) Effect of Everolimus Introduction on Cardiac Allograft Vasculopathy-Results of a Randomized, Multicentre Trial. Transplantation, 92, 235-243. http://dx.doi.org/10.1097/TP.0b013e31822057f1

[20] Hilbrands, L.B., Dernacker, P.N., Hoitsma, A.J., Stalenhoef, A.F. and Koene, R.A. (1995) The Effects of Cyclosporine and Prednisone on Serum Lipid and (Apo)lipoprotein Levels in Renal Transplant Recipients. Journal of the American Society of Nephrology, 5, 2073.

[21] Mehra, M.R., Ventura, H.O., Smart, F.W., Collins, T.J., Ramee, S.R. and Stapleton, D.D. (1995) An Intravascular Ultrasound Study of the Influence of Angiotensin-Converting Enzyme Inhibitors and Calcium Entry Blockers on the Development of Cardiac Allograft Vasculopathy. American Journal of Cardiology, 75, 853-854. http://dx.doi.org/10.1016/S0002-9149(99)80432-9

[22] Pethig, K., Horing, B., Bara, C., Schieffer, B., Haverich, A. and Sachse, A. (2008) Eprosartan in the Primary Prevention of Cardiac Allograft Vascular Disease: A Double-Blind Prospectively Randomized Study Using Intravascular Ultrasound. Journal of International Medical Research, 36, 1022-1031. http://dx.doi.org/10.1177/147323000803600520

[23] Yamamoto, T., Sata, M., Fukuda, D. and Takamoto, S. (2006) The Angiotensin II Type 1 Receptor Blocker Candesartan Attenuates Graft Vasculopathy. Journal of Surgical Research, 132, 62-68. http://dx.doi.org/10.1016/j.jss.2005.07.011

[24] Grigioni, F., Potena, C.L., Fabbri, F., Russo, A., Muauraca, A.C., Coccolo, F. and Magnani, G. (2006) Long-Term Safety and Effectiveness of Statin for Heart Transplant Recipients in Routine Clinical Practice. Transplantation Proceedings, 38, 1507-1510. http://dx.doi.org/10.1016/j.transproceed.2006.02.071

[25] Kobagashi, J.A., Moriguichi, J.D., Laks, H., Wener, L., Hage, A., Hamilton, M.A., Cogert, G., Marquez, A., Vasstlakis, M.E., Patel, J. and Yeatman, L. (2005) Ten-Year Follow-Up of a Randomized Trial of Pravastatin in Heart Transplant Patients. The Journal of Heart and Lung Transplantation, 24, 1736-1740. http://dx.doi.org/10.1016/j.healun.2005.02.009

[26] Patel, D.N., Pagnani, F.D., Koelling, T.M., Dyke, D.B., Baliga, R.R., Cody, R.J., Lake, K.D. and Aaronson, K.D. (2002) Safety and Efficacy of Atorvastatin in Heart Transplant Recipients. The Journal of Heart and Lung Transplantation, 21, 204-210. http://dx.doi.org/10.1016/S1053-2498(01)00369-2

[27] Mehra, M.R., Uber, P.A., Vivekananthan, K., Solis, S., Soctt, R.L., Park, M.H., Milani, R.V. and Lavie, C.J. (2002) Comparative Beneficial Effects of Simvastatin and Pravastatin on Cardiac Allograft Rejection and Survival. Journal of the American College of Cardiology, 40, 1609-1614. http://dx.doi.org/10.1016/S0735-1097(02)02340-9

[28] Anderson, T.J., Grégoire, J., Hegele, R.A., Couture, P., Mancini, G.B., McPherson, R., Francis, G.A., Poirier, P., Lau, D.C., Grover, S., Genest Jr., J., Carpentier, A.C., Dufour, R., Gupta, M., Ward, R., Leiter, L.A., Lonn, E., Ng, D.S., Pearson, G.J., Yates, G.M., Stone, J.A. and Ur, E. (2013) 2012 Update of the Canadian Cardiovascular Society Guidelines for the Diagnosis and Treatment of Dyslipidemia for the Prevention of Cardiovascular Disease in the Adult. Canadian Journal of Cardiology, 29, 151-167. http://dx.doi.org/10.1016/j.cjca.2012.11.032

[29] Olmetti, F., Pinna, G.D., Maestri, R., D’Armini, A., Pellgrinni, C., Vigano, M. and Lilleri, D. (2011) Heart Rate and Cardiac Allograft Vasculopathy in Heart Transplant Recipients. The Journal of Heart and Lung Transplantation, 30, 1368-1373. http://dx.doi.org/10.1016/j.healun.2011.07.009

[30] Sander, M. and Victor, R.G. (1995) Hypertension after Cardiac Transplantation: Pathophysiology and Management. Current Opinion in Nephrology and Hypertension, 4, 443-451.

[31] Sanchez-Lazaro, I.J., Martınez-Dolz, L., Almenar-Bonet, L., Moro-Lopez, J.A., Aguero, J., Ortiz-Martınez, V., Iz- 
quierdo, M.T. and Salvador, A. (2008) Predictor Factors for the Development of Arterial Hypertension Following Heart Transplantation. Clinical Transplantation, 22, 760-764. http://dx.doi.org/10.1111/j.1399-0012.2008.00875

[32] Radermacher, J.R., Meiners, M., Bramlage, C., Kliena, V. and Behrend, M. (1998) Pronounced Renal Vasoconstriction and Systemic Hypertension in Renal Transplant Patients Treated with Cyclosporin A versus Tacrolimus. Transplantation, 11, 3-10. http://dx.doi.org/10.1111/j.1432-2277.1998.tb00948.x

[33] Taylor, D.O., Barr, M.L., Radovancevic, B., Renlund, D.G. and Mentzer, R.M. (1999) Randomized Control Trial Comparing Tacrolimus and Cyclosporine A in Cardiac Transplant Recipients. The Journal of Heart and Lung Transplantation, 18, 336-345. http://dx.doi.org/10.1016/S1053-2498(98)00060-6

[34] Brozena, S.C., Johnson, M.R., Ventura, H., Hobbs, R., Miller, L., Olivari, M.T. and Clemson, B. (1996) Effectiveness and Safety of Diltiazem or Lisinopril in Treatment of Hypertension after heart Transplantation. Journal of the American College of Cardiology, 27, 1701-1712. http://dx.doi.org/10.1016/0735-1097(96)00057-5

[35] Leenen, F.H.H., Coletta, E. and Davies, R.A. (2007) Prevention of Renal Dysfucntion and Hypertension by Amlodipine after Heart Transplant. American Journal of Cardiology, 100, 531-535. http://dx.doi.org/10.1016/j.amjcard.2007.03.058

[36] Opie, L.H., Haus, M., Commerfod, P.J., Levetan, B., Moore, K. and Brink, J. (2002) Antihypertensive Effects of Angiotensin Converting Enzyme Inhibition by Lisinopril in Post-Transplant Patients. American Journal of Hypertension, 15, 911-916. http://dx.doi.org/10.1016/S0895-7061(02)02992-8

[37] White, M., Ross, H., Levesque, S., Whittom, L., Pelletier, G.B., Racine, N., Meloche, S. and Voisin, L. (2009) Effects of Angiotensin-Converting Enzyme Inhibitors versus Valsartan on Cellular Signaling Events in Heart Transplant. Annals of Pharmacotherapy, 43, 831-839. http://dx.doi.org/10.1345/aph.1L602

[38] Schroeder, J.S., Gao, S.Z., Alderman, E.L., Hunt, S.A., Johnstone, I., Boothroyd, D.B., Wiederhold, M.A. and Stinson, E.B. (1993) A Preliminary Study of Diltiazem in the Prevention of Coronary Artery Disease in Heart-Transplant Recipients. The New England Journal of Medicine, 328, 164-170. http://dx.doi.org/10.1056/NEJM199301213280303

[39] Rudas, L., Pflugfeider, P.W., McKenzie, N., Menkins, A.H., Novick, R.J. and Kostuk, W.J. (1990) Serial Evaluation of Lipid Profiles and Risk Factors for Development of Hyperlipidemia after Cardiac Transplantation. American Journal of Cardiology, 66, 1135-1136. http://dx.doi.org/10.1016/0002-9149(90)90518-6

[40] Zakliczynaki, M., Bogualaweka, J., Wojniak, E., Zakliczyneka, H., Ciesla, D. and Nozynski, J. (2011) In the Era of Universal Use of Statins Dyslipidemia's Are Still Common in Heart Transplant Recipients: A Cross-Sectional Study. Transplantation Proceedings, 43, 3071-3073. http://dx.doi.org/10.1016/j.transproceed.2011.08.052

[41] Magnani, G., Carinci, V., Magelli, C., Potena, L., Reggiani, L.B. and Branzi, A. (2000) Role of Statins in the Management of Dyslipidemia after Cardiac Transplant: Randomized Controlled Trial Comparing the Efficacy and the Safety of Atorvastatin with Pravastatin. The Journal of Heart and Lung Transplantation, 19, 710-715. http://dx.doi.org/10.1016/S1053-2498(00)00128-5

[42] Grigioni, F., Carigi, S., Potena, L., Fabbri, F., Russo, A., Musuraca, A.C., Coccolo, F. and Magnani, G. (2006) LongTerm Safety and Effectiveness of Statins for Heart Transplant Recipients in Routine Clinical Practice. Transplantation Proceedings, 38, 1507-1510. http://dx.doi.org/10.1016/j.transproceed.2006.02.071

[43] Manipisitkul, W., McCann, E., Lee, S. and Weir, M.R. (2009) Drug Interactions in Transplant Patients: What Everyone Should Know. Current Opinion in Nephrology and Hypertension, 18, 404-411. http://dx.doi.org/10.1097/MNH.0b013e32832edcb2

[44] Mignat, C. (1997) Clinically Significant Drug Interactions with New Immunosuppressive Agents. Drug Safety, 16, 267-278. http://dx.doi.org/10.2165/00002018-199716040-00004

[45] Wu, A.H., Ballantyne, C.M., Short, B.C., Torre-Amione, G., Young, J.B. and Ventura, H.O. (2005) Statin Use and Risks of Death or Fatal Rejection in the Heart Transplant Lipid Registry. American Journal of Cardiology, 95, $367-372$. http://dx.doi.org/10.1016/j.amjcard.2004.09.035

[46] Bergman, E., Lundahl, A., Fridblom, P., Hedeland, M. and Bondesson, U. (2009) Enterohepatic Disposition of Rosuvastatin in Pigs and the Impact of Concomitant Dosing with Cyclosporine and Gemfibrozil. American Society for Pharmacology and Experimental Therapeutics, 37, 2349-2358. http://dx.doi.org/10.1124/dmd.109.029363

[47] Lemahieu, W.P.D., Hermann, M., Asberg, A., Verbeke, K., Holdaas, H., Vanrenterghem, Y. and Maes, B.D. (2005) Combined Therapy with Atorvastatin and Calcineurin Inhibitors: No Interactions with Tacrolimus. American Journal of Transplantation, 5, 2236-2243. http://dx.doi.org/10.1111/j.1600-6143.2005.01005.X

[48] Crespo-Leiro, M.G., Paniagua, M.J., Marzoa, R., Grille, Z., Naya, C., Flores, X. and Rodriguez, J.A. (2008) The Efficacy and Safety of Ezetimibe for Treatment of Dyslipidemia after Heart Transplantation. Transplantation Proceedings, 40, 3060-3062. http://dx.doi.org/10.1016/j.transproceed.2008.09.007

[49] Thiebald, D., Krieg, M.A., Gillard-Berguer, D., Jacquet, A.F., Goy, J.J. and Burckhardt, P. (1996) Cyclosporine Induces High Bone Turnover and May Contribute to Bone Loss after Heart Transplantation. European Journal of Clini- 
cal Investigation, 26, 549-55. http://dx.doi.org/10.1046/j.1365-2362.1996.00170.x

[50] Cohen, A., Addonizio, L.J., Lamour, J.M., Addesso, V., Staron, R.B., Goa, P. and Shane, E. (2005) Osteoporosis in Adult Survivors of Adolescent Cardiac Transplantation May Be Related to Hyperparathyroidism, Mild Renal Insufficiency and Increased Bone Turnover. The Journal of Heart and Lung Transplantation, 24, 696-702. http://dx.doi.org/10.1016/j.healun.2004.03.020

[51] Pisani, B. and Mullen, M. (2002) Prevention of Osteoporosis in Cardiac Transplant Recipients. Current Opinion in Cardiology, 17, 160-164. http://dx.doi.org/10.1097/00001573-200203000-00006

[52] Homik, J., Cranney, A., Shea, B., Tugwell, P., Wells, G.A., Adachi, J. and Suarez-Almazor, M.E. (2000) Bisphosphonates for Steroid Induced Osteoporosis. The Cochrane Database of Systematic Reviews, 2, Article ID: CD001347.

[53] Kapetanakis, E.I., Antonpoulos, A.S., Antoniou, T.A., Theodoraki, K.A., Zarkallas, D. and Sfirakas, P.D. (2005) Effect of Long-Term Calcitonin Administration on Steroid-Induced Osteoporosis after Cardiac Transplantation. The Journal of Heart and Lung Transplantation, 24, 526-532. http://dx.doi.org/10.1016/j.healun.2004.02.016

[54] Braith, R.W., Magyari, P.M., Fulton, M.N., Lisor, C.F., Vogel, S.E., Hill, J.A. and Aranda, J.M. (2006) Comparison of Calcitonin versus Calcitonin and Resistance Exercise as Prophylaxis for Osteoporosis in Heart Transplant Recipients. Transplantation, 81, 1191-1195. http://dx.doi.org/10.1097/01.tp.0000176927.43937.bb 
Scientific Research Publishing (SCIRP) is one of the largest Open Access journal publishers. It is currently publishing more than 200 open access, online, peer-reviewed journals covering a wide range of academic disciplines. SCIRP serves the worldwide academic communities and contributes to the progress and application of science with its publication.

Other selected journals from SCIRP are listed as below. Submit your manuscript to us via either submit@scirp.org or Online Submission Portal.
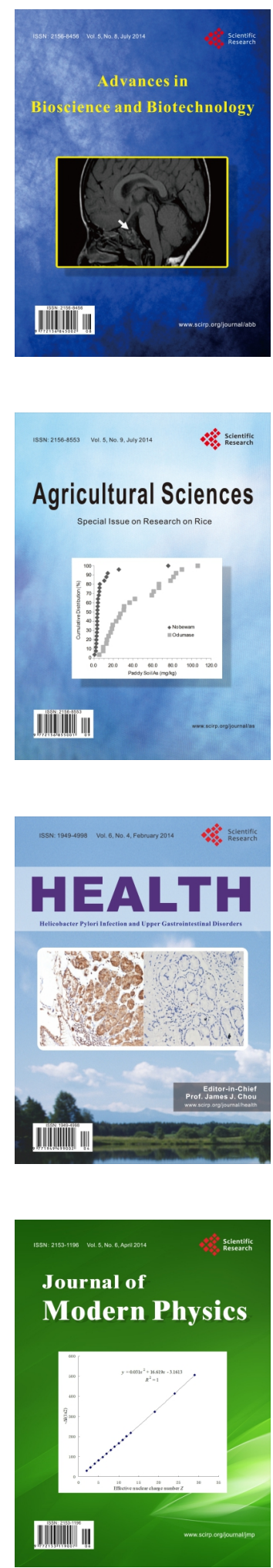
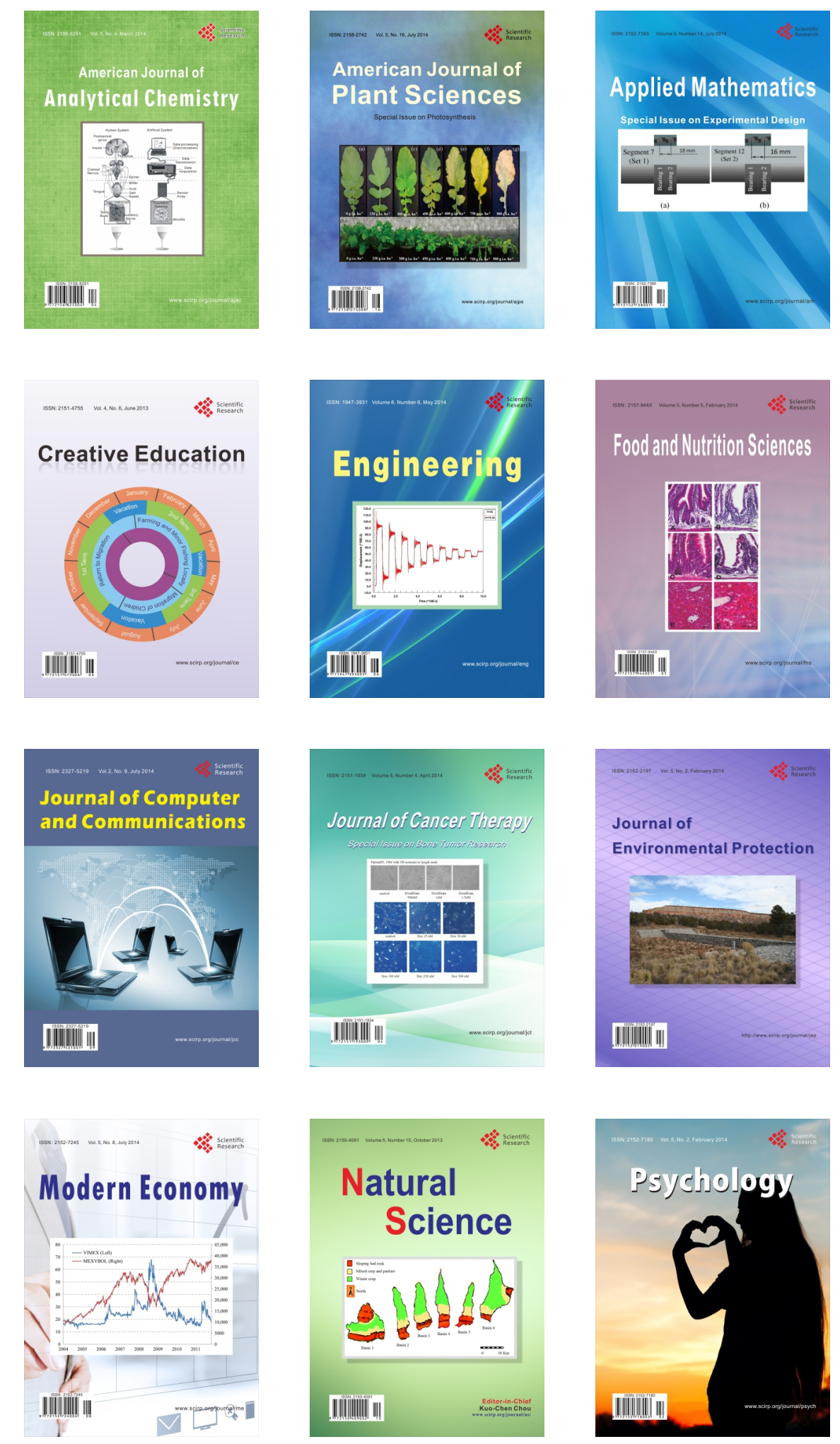